\title{
Lenzites elegans KSG32: a novel white rot fungus for synthetic dye decolourization
}

\begin{abstract}
Lenzites elegans, a ligninolytic enzyme producing white rot fungus with proficient synthetic dye decolourization ability was isolated from decaying wood. To the extent of our knowledge, this is the first report of laccase $(362.7 \mathrm{IU} / \mathrm{mL})$ and lignin peroxidase $(5.17 \mathrm{IU} / \mathrm{mL})$ production by $L$. elegans $\mathrm{KSG} 32$. The synthetic dye decolorizing ability of the fungus was checked using solid and liquid media. The organism showed greater ability for decolourization of naphthol green B (97\%) and bromophenol blue (88\%) in the submerged condition followed by partial decolourization for two azo dyes, namely, orange $\mathrm{G}(70 \%)$ and congo red (62\%). This is an indicative of the potential application of L. elegans KSG32 in decolourization of colored industrial effluent. The FTIR analysis of the decolourized dye sample showed that major bonds in the dye were broken and oxidation process also increased. The analysis of biomass content showed no growth inhibition of $L$. elegans KSG32 in the presence of dyes, indicating the less toxicity of these dyes on fungal growth.
\end{abstract}

Keywords: ligninolytic fungi, laccase, lignin peroxidase, synthetic dyes, decolorization, FTIR
Volume 5 Issue 3 - 2017

\section{Kiran Lakshmi MS, Soumya PS, Akhila Shaji, Padma Nambisan}

Kiran Lakshmi MS, Soumya PS, Akhila Shaji, Padma Nambisan

Correspondence: Padma Nambisan, Department of Biotechnology, Cochin University of Science and Technology, Cochin- 682022, Kerala, India, Tel +919446535I5I, Email plantbiotech1992@gmail.com

Received: July 20, 2017 | Published:September II, 2017

\section{Introduction}

Synthetic dyes are complex aromatic compounds used in many industries like paper, printing, textile, food and cosmetics. ${ }^{1}$ The major synthetic dyes include azo, triphenylmethane, anthraquinone and metal dyes. They are reported to be carcinogenic and thus their safe release into the environment poses a threat to public health. About 10 $15 \%$ of the substrate unbound dyes from the industries are discharged into water bodies without any effective treatment. ${ }^{2}$ The release of these effluents into water bodies affects all biological systems. ${ }^{3}$ The removal or degradation of these dyes can be done by both physical and chemical methods. But the production of secondary pollutants like sludge and toxic compounds discourages the use of such costly methods. ${ }^{4}$ These disadvantages can be overcome by adopting biological methods or green strategies. The most cost-effective and eco-friendly approach is the removal of these dyes by various microorganisms and associated degrading enzymes. ${ }^{5}$

Ligninolytic fungi possess an enzyme system which is a combination of lignin peroxidase ( $\mathrm{LiP})$, manganese peroxidase $(\mathrm{MnP})$ and laccase. LiP and MnP are extracellular hemeproteins. LiPs have unusually high redox potential and low optimum $\mathrm{pH} .{ }^{6-9} \mathrm{LiP}$ is capable of oxidizing a variety of reducing substrates including polymeric substrates and non-phenolic aromatic compounds. ${ }^{10} \mathrm{MnPs}$ catalyze the oxidation of $\mathrm{Mn} 2+$ to $\mathrm{Mn} 3+$, which is a strong oxidant that can oxidize phenolic and aromatic amines, yielding organic radicals. ${ }^{11}$ Laccases are extracellular multicopper oxidoreductase ${ }^{12}$ that can act on a broad range of substrates, including phenols, phenolic compounds, diamines, aromatic amines, benzenethiol and even some inorganic compounds such as iodine. ${ }^{13}$ Due to these unusual properties, ligninolytic enzymes are effective in degrading/decolourising synthetic dyes. ${ }^{14-16}$ White rot fungi coming under basidiomycetes are good producers of ligninolytic enzymes. Most of them are edible and have medicinal properties.

The present study deals with the isolation of a fungal strain producing ligninolytic enzyme followed by the screening for decolorization properties by the selected microorganism.

\section{Materials and methods}

\section{Collection and isolation of fungal strains}

Thirty-two visibly different fungal fruiting bodies were collected from decaying wood and soil litter from various locations of Kerala (Kasaragod, Kangarappady, Ernakulam, Kottayam and Mangalavanam). To obtain pure cultures, small fragments from the inner flesh of the fruiting body were excised and plated onto potato dextrose agar (PDA) (Himedia, Mumbai) plates after surface sterilization with $70 \%$ ethanol. Pure cultures were obtained by repeated and successive transfer of mycelia onto new agar plates and were stored at $4^{\circ} \mathrm{C}$ on PDA plates.

\section{Screening for production of ligninolytic enzymes}

The isolates were grown on lignin containing basal agar medium. The strains growing on this medium were selected for secondary screening, both quantitative and qualitative methods. The qualitative screening was done using PDA plates containing $0.0025 \% \mathrm{w} / \mathrm{v}$ Azure $\mathrm{B}$ for detecting lignin peroxidase production, ${ }^{17}$ and $0.02 \%$ guaiacol for detecting laccase production. ${ }^{18}$

The quantitative screening was done by solid state fermentation (SSF). Pineapple leaves were selected as the substrate for SSF. The leaves were cut to equal size $(5 \times 1 \mathrm{~cm})$ and autoclaved at $121{ }^{\circ} \mathrm{C}$ for $15 \mathrm{~min}$. The moisture content was adjusted to $90 \%$ using $0.1 \mathrm{M}$ citrate buffer ( $\mathrm{pH} 5$ ). Three mycelial plugs of size $1 \mathrm{~cm}^{2}$ from 6days old PDA plate culture were used as inoculum. Inoculated flasks were incubated at room temperature for 5 days.

\section{Extraction of crude enzyme}

After incubation, the crude enzyme was extracted by adding $50 \mathrm{~mL}$ $0.1 \mathrm{M}$ citrate buffer ( $\mathrm{pH} 5$ ) to each flask. The culture supernatant was collected after centrifugation at $10,000 \mathrm{rpm}$ for $10 \mathrm{~min}$ at $4^{\circ} \mathrm{C}$ and stored at $4^{\circ} \mathrm{C}$. 


\section{Enzyme assays}

The activity of LiP, MnP and laccase were checked for each crude extract. LiP activity was measured by the method of $\mathrm{H} 2 \mathrm{O} 2$ dependent oxidation of veratryl alcohol to veratraldehyde. The increase in absorbance was checked at $310 \mathrm{~nm}$. MnP activity was determined by the method using phenol red as substrate. The absorbance was checked at $610 \mathrm{~nm} .{ }^{19}$ Laccase activity was measured by the oxidation of ABTS (2, 2'-azino-bis(3-ethyl-benzothiazoline-6-sulphonic acid)). The absorbance was checked at $420 \mathrm{~nm} \cdot{ }^{20}$

Enzyme activity was expressed in international units (IU/mL). One IU of enzyme activity was defined as the amount of enzyme that oxidized $1 \mu \mathrm{M}$ of substrate perminute under standard conditions.

\section{Identification of selected strain}

DNA was isolated from the strain KSG 32 by the modified method of. ${ }^{21}$ The isolated DNA was subjected to $18 \mathrm{~S}$ rDNA amplification using ITS1 and ITS4 primers. ${ }^{22}$ The reaction mixture contains $25 \mathrm{mM}$ $\mathrm{MgCl} 2,2 \mathrm{mM}$ dNTP, $1 \mathrm{X}$ Taq buffer, $0.5 \mu \mathrm{M}$ of each primer, 1unit of Taq polymerase and $100 \mathrm{ng}$ of template DNA. The polymerase chain reaction was performed by initial denaturation for $5 \mathrm{~min}$ at $94^{\circ} \mathrm{C}$ followed by 30 cycles of denaturation at $94^{\circ} \mathrm{C}$ for $30 \mathrm{sec}$, annealing at $55^{\circ} \mathrm{C}$ for $2 \mathrm{~min}$, extension at $72^{\circ} \mathrm{C}$ for $3 \mathrm{~min}$ and a final extension at $72^{\circ} \mathrm{C}$ for $10 \mathrm{~min}$. The PCR product sequencing was performed on an ABI 3730XL DNA sequencer. The sequence data were submitted to the NCBI database and accession number obtained (GenBank Accession no. KP262029).

The molecular identification of KSG 32 was done by comparing the amplified 18S rDNA sequence with the sequences available in the NCBI nucleotide databases using BLAST (Basic Local Alignment Search Tool) algorithm. ${ }^{23}$

\section{Dye decolorization experiments}

Decolorization studies on various dyes by L. elegans KSG32 were conducted on both PDA and PDB. Initially the ability of $L$. elegans KSG32 to grow in the presence of various dyes was carried out by growing them on dye incorporated PDA plates. The dyes used were bromophenol blue (SRL, Mumbai), naphthol green B (HiMedia, Mumbai), orange G (HiMedia, Mumbai) and congo red (SRL, Mumbai). The dyes were filter sterilized and added to the sterilized PDA at a final concentration of $0.05 \mathrm{~g} / \mathrm{L}$. The dye incorporated plates were inoculated using $0.5 \mathrm{~cm}^{2}$ mycelial plug from 6-day old culture. The plates were incubated at $28^{\circ} \mathrm{C}$ for 10 days.

In the case of decolourization on PDB, the dyes were added to the medium by either of two methods: a) at the time of inoculation and b) to 5-day old cultures at a final concentration of $0.05 \mathrm{~g} / \mathrm{L}$. The flasks were incubated up to 12 days with intermittent shaking at $28^{\circ} \mathrm{C}$. At regular intervals, $1 \mathrm{~mL}$ samples were withdrawn from the flasks and centrifuged at $10,000 \mathrm{rpm}$ for $10 \mathrm{~min}$. The supernatants were analyzed for the change in absorbance at the absorbance maxima $(\lambda \max )$ of each dye using a UV-visible spectrophotometer (Shimatzu). The $\lambda \max$ of, orange $G$ and congo red is $612 \mathrm{~nm}, 591 \mathrm{~nm}, 448 \mathrm{~nm}$ and $354 \mathrm{~nm}$ respectively.

The percentage of decolorization was calculated in accordance with the following equation: ${ }^{24}$

Percentage decolorization $=$ (Initial absorbance - Observed absorbance/ initial absorbance $) \times 100$
Toxicity studies of the dyes on fungal growth was monitored during the course of study in terms of biomass content. This was done prior to the decolorization studies in PDB. The toxicity studies were also conducted at a final concentration of $0.05 \mathrm{~g} / \mathrm{L}$. Biomass was evaluated by determining the dry weight of mycelia. The culture solution was filtered through pre weighed Whatman no. 1 filter paper. The filtered fungal mass was dried at $70^{\circ} \mathrm{C}$ to a constant weight. The biomass was expressed in $\mathrm{g} / \mathrm{L}$.

The enzyme activity during the growth of fungi in control and dye containing PDB on each day of incubation was observed.

\section{FTIR analysis}

For Fourier Transform Infrared Spectroscopy (FTIR) analysis, the dye control and decolorized solutions were extracted using an equal volume of ethyl acetate and dried over anhydrous sodium sulphate. The extracts were then dissolved in methanol and used for FTIR analysis (Thermo Nicolet, Avatar 370) in the mid infrared region of $400-4000 \mathrm{~cm}-1$ with a resolution of $4.0 \mathrm{~cm}^{-1}$.

\section{Statistical analysis}

All the experiments were performed in triplicates and its statistical significance was checked by performing one-way analysis of variance (ANOVA) with Tukey-Kramer post Hoc test using the SPSS 19 software (SPSS Inc.). Probability values $<0.05$ were considered to be significant.

\section{Results}

\section{Screening for ligninolytic enzymes}

A total of 23 isolates were selected, based on their ability to grow on lignin containing basal media for secondary screening. The oxidative depolymerization of guaiacol forms reddish brown zone by laccase producing strains (Figure 1A), while green colored zones are observed with lignin peroxidase producing strains due to the oxidation of azure B (Figure 1B).

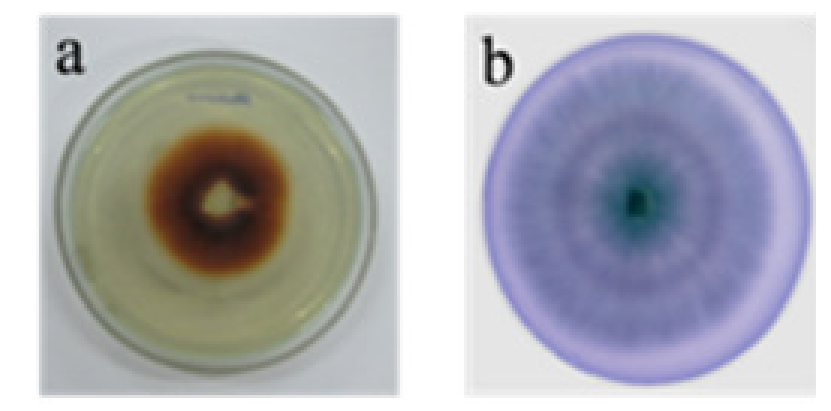

Figure I Qualitative analysis of Laccase and LiP by Lenzites elegansKSG32: (a) Oxidative depolymerization of guaiacol by laccase form reddish brown zone; (b) Oxidation of Azure B by lignin peroxidase to form green zone.

In quantitative screening, these 23 selected isolates were subjected to SSF using pineapple leaves and checked for enzyme production. The enzyme activity for LiP, laccase and $\mathrm{MnP}$ in the crude extract are shown in Table 1. After the secondary screening, 9 organisms were found to produce all three ligninolytic enzymes. The production of $\mathrm{MnP}$ by most of the isolates was found to be negligible in comparison with LiP and laccase. The strain KSG32 was observed to be having higher laccase $(362.7 \mathrm{IU} / \mathrm{mL})$ and $\mathrm{LiP}(5.17 \mathrm{IU} / \mathrm{mL})$ activity and was thus selected for further studies. 
Table I The mycelial growth and decolorization zone on PDA plates 4days after inoculation of Lenzites elegans KSG32

\begin{tabular}{lll}
\hline Synthetic dye & $\begin{array}{l}\text { Mycelial growth } \\
\text { diameter }(\mathbf{c m})\end{array}$ & $\begin{array}{l}\text { Decolourization } \\
\text { zone }(\mathbf{c m})\end{array}$ \\
\hline Control & $8.2 \pm 0.15$ & - \\
Naphthol green B & $8.2 \pm 0.1$ & $7.6 \pm 0.2$ \\
Bromophenol blue & $7.07 \pm 0.11$ & $4.7 \pm 0.12$ \\
Orange G & $7.83 \pm 0.11$ & $4.7 \pm 0.1$ \\
Congo red & $7.67 \pm 0.15$ & - \\
\hline
\end{tabular}

\section{Identification of the selected strain KSG32}

The growth of KSG32 on PDA plate had a regular margin and white color. A woolly mat was formed behind the margins. Concentric rings were also observed (Figure 2A). Hyphal structures and characteristics observed under microscopy showed long skeletal hyphae with irregular branching pattern. Clamp connections were also observed (Figure 2B). The basidiospores were an oblong ellipsoid.
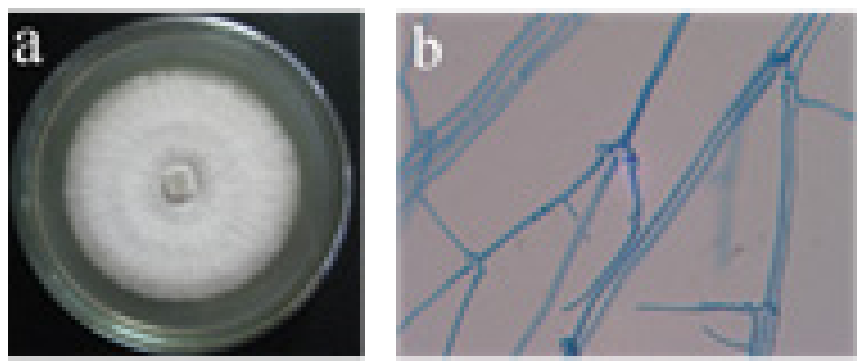

Figure 2 (a) Lenzites elegans on PDA plate; (b) Hyphal structure (under 40X).

The molecular identification of KSG32 was done by $18 \mathrm{~S}$ rDNA amplification. Following the BLAST analysis, the isolate was identified to be L. elegans.

\section{Dye decolorization studies on agar plates}

During the initial studies on dye incorporated PDA plates, $L$. elegans KSG32 showed sufficient growth indicating that the fungal growth was not retarded by the dyes. The growth of L. elegans KSG32 on dye containing PDA plates resulted in decolorization zones. A complete decolorization zone was observed in the naphthol green B containing plates. Partial decolorizing zones were observed in orange $\mathrm{G}$, congo red and bromophenol blue containing PDA plates. The growth pattern on the fourth day of inoculation on PDA plates is shown in Figure 3. The mycelial growth diameter and decolorization zone were noted in Table 1.

\section{Toxicity studies on fungal growth in terms of biomass content}

For the toxicity studies, dyes were added either at the time of inoculation (Figure 4A) or on the fifth day after inoculation (Figure 4B). When the dyes were added at the time of inoculation, the biomass content in the dye containing medium was similar to that of control. Whereas when the dyes were added to the 5-day old culture the biomass content was higher than control, except in bromophenol blue containing media in which the biomass content in the test remains similar to that of the control.

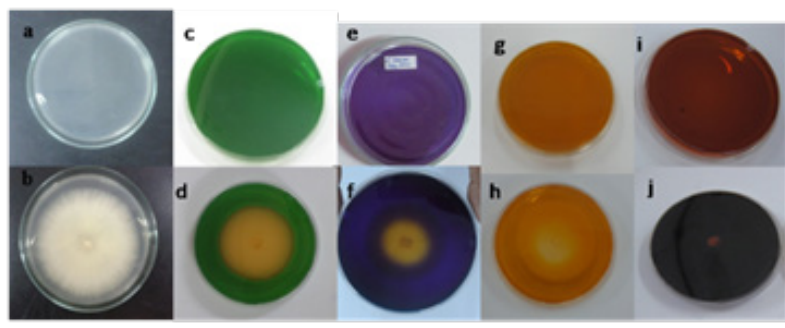

Figure 3 Decolorization studies 4 days after inoculation on PDA plates; (a) Control PDA plate; (b) mycelial growth on PDA plate; (c) Control plate containing naphthol green B; (d) Decolourization zone on naphthol green $B$ plate; (e) Control plate containing bromophenol blue; (f) Decolourization zone on bromophenol blue plate; (g) Control plate containing orange G; $(\mathrm{h})$ Decolourization zone on orange $\mathrm{G}$ plate; (i) Control plate containing congo red; (j) Mycelial growth on congo red plate.

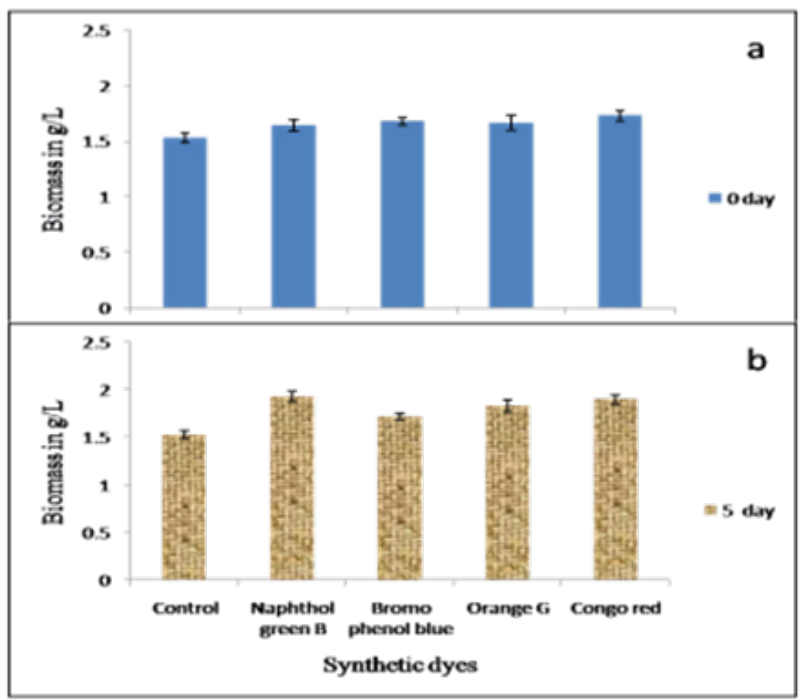

Figure 4 Biomass content 12days after inoculation: (a) Dyes added at the time of inoculation; (b) Dyes added on fifth day after inoculation.

\section{Dye decolorization in liquid culture media}

Inorder to quantitatively analyze the ability of L. elegans KSG32 to decolourise dye solutions, the dyes were added to the liquid culture medium. The culture supernatant was analyzed spectro photometrically on daily basis for 12days. L. elegans KSG32 was capable of decolorizing all the dyes used in the study (Figure 5). In 4days of incubation $94 \%$ of naphthol green B was decolorized, while $88 \%$ of bromophenol blue decolorization occurred in 7 -day. When incubated for 12 days, $70 \%$ orange $\mathrm{G}$ and $48 \%$ of congo red decolorization was observed. Decolorization of orange $\mathrm{G}$ starts after 7 days of incubation. Congo red was the least decolorized as only $48 \%$ decolorization occurred. The statistical analysis was done by ANOVA and Tukey-Kramer multiple comparison tests by SPSS software using the mean values of decolorization percentage of all four dyes used in the study. The decolourization percentage of naphthol green B, orange $\mathrm{G}$, congo red were significantly different, while that of naphthol green $\mathrm{B}$ and bromophenol blue do not show any significant difference.

\section{FTIR spectra analysis}

The FTIR spectra of naphthol green B extract from control (a) and after decolorization experiment (b) are shown in Figure 7. The spectrum of the decolourised extract showed significant difference with that of the control. 


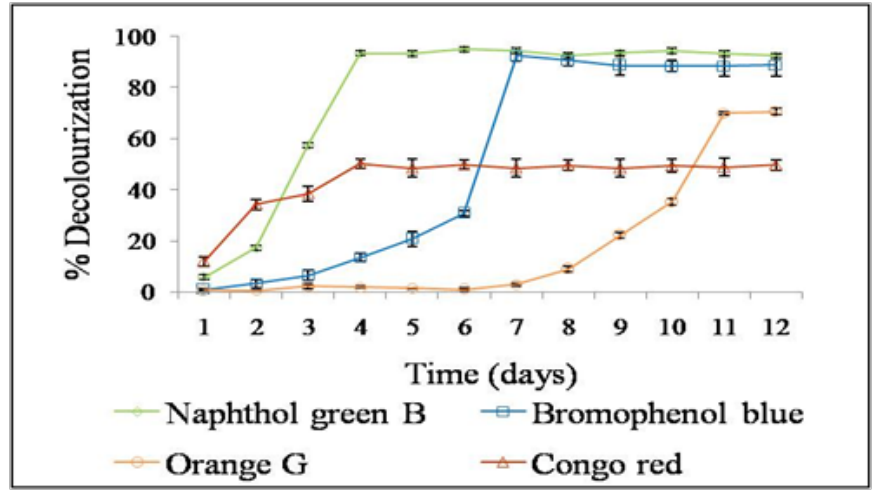

Figure 5 Decolorization effect on dyes when added at the time of inoculation to the Lenzites elegans culture.

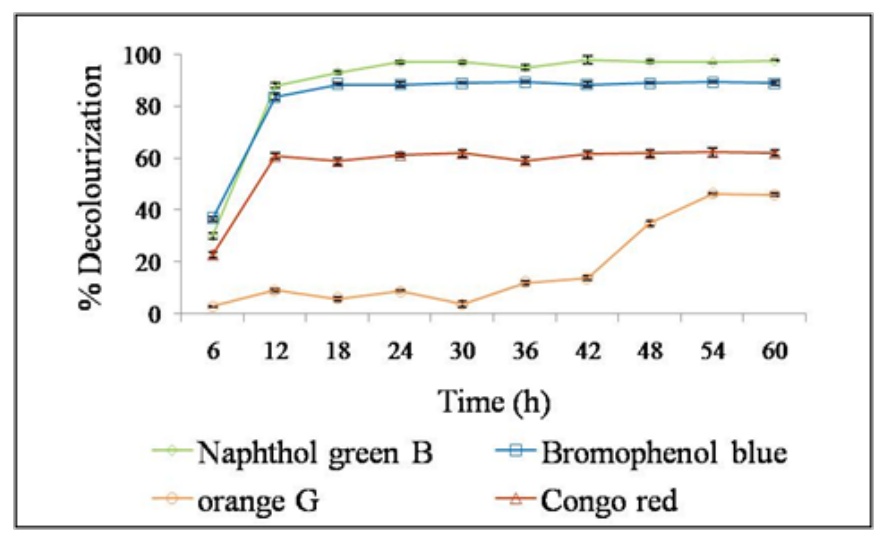

Figure 6 Decolorization effect on dyes when added to the 5 days old Lenzites elegans KSG32 culture.

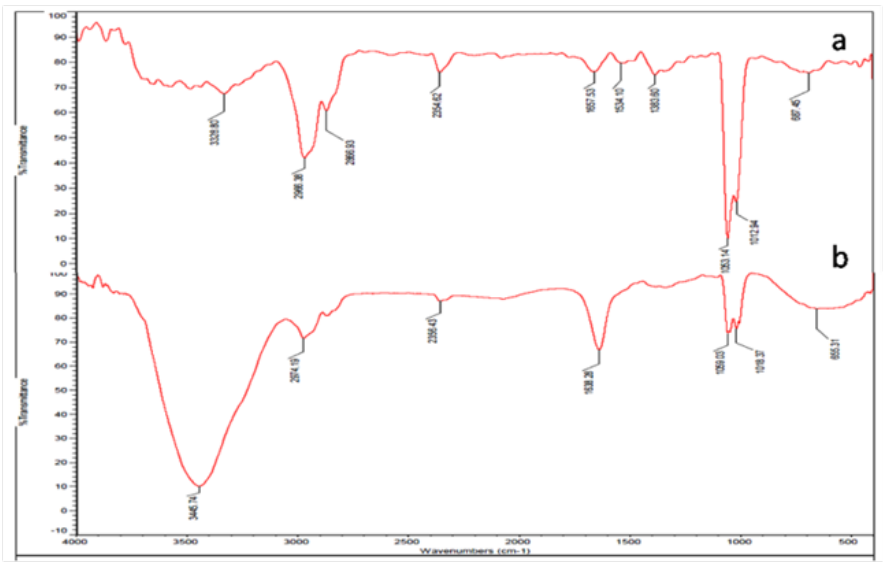

Figure 7 FTIR analysis of naphthol green B: (a) dye control; (b) after decolorization.

\section{Enzyme activity during decolorization}

Figure 8 shows the significant role of enzyme activity during the growth of the organism in decolorization. There are two aspects for decolorization by fungi, biosorption and enzymatic degradation. In the present study, adsorption of dyes to the mycelium was not observed visually. The presence of laccase and LiP was observed and enzyme activities were monitored daily in control and a dye containing fungal cultures. An increase in laccase activity was observed in the presence of dyes (except for orange G) while LiP activity decreased in the presence of dyes. When the dyes were added to the 5-day old culture, laccase activity increased until the maximum decolorization occurred after that the activity stabilized. This confirms the increased laccase activity in presence of synthetic dyes.

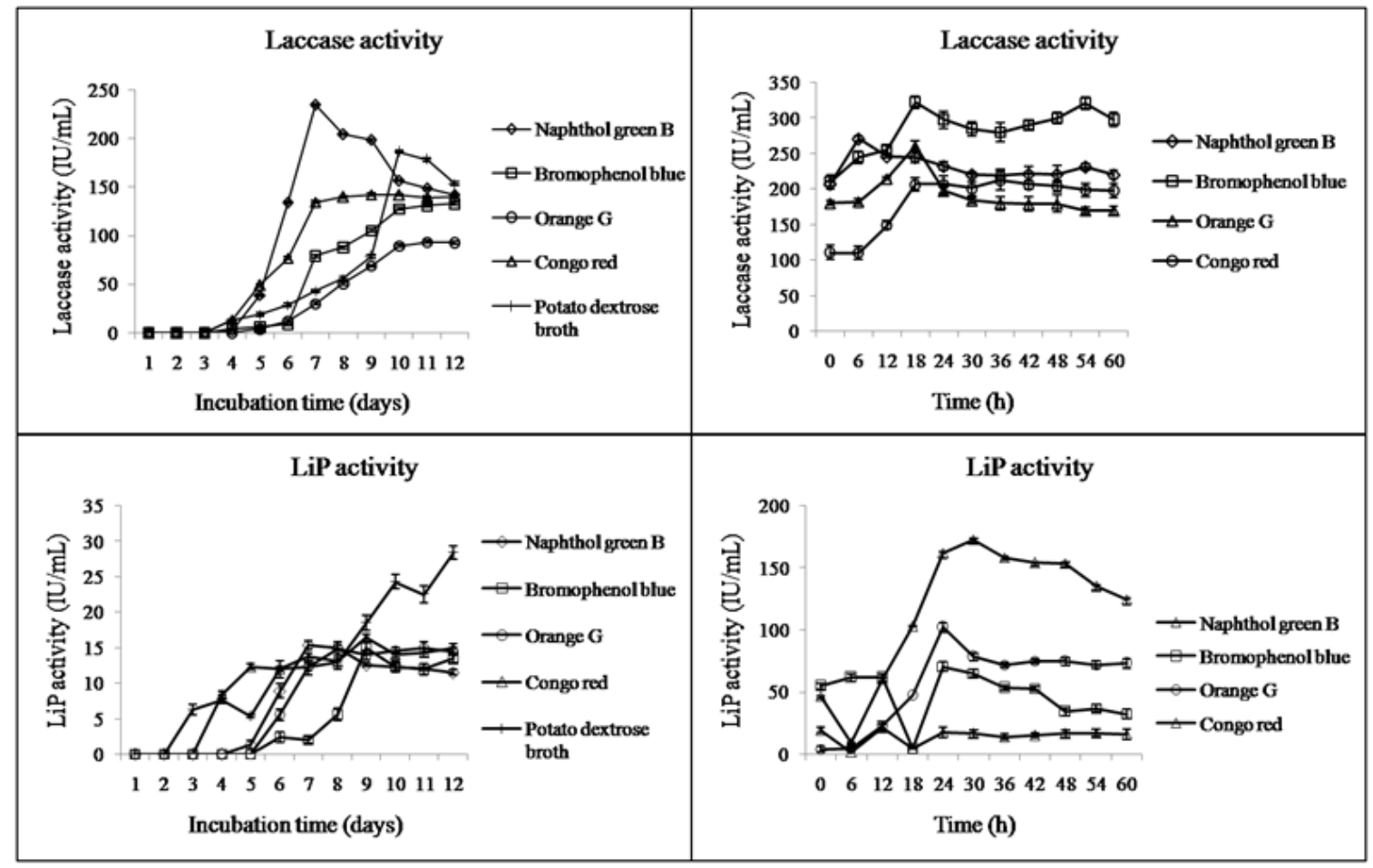

Figure 8 Enzyme activities during the growth of organism in dye containing media. (a) Laccase activity on each day of incubation; (b) Laccase activity on dye addition to 5 day old culture; (c) LiP activity on each day of incubation; (d) LiP activity on dye addition to 5 day old culture. 


\section{Discussion}

In this study, we found that our isolate L. elegans KSG32, which has been isolated from degrading wood showed higher ligninolytic enzyme production. There are numerous reports on the production of ligninolytic enzymes by basidiomycetes. Several species of white rot basidiomycetes such as Trametes sp., Schizophyllum sp., Pleurotus sp., Ganoderma lucidum produce high amount of these enzymes. ${ }^{18-21}$ This is the first report on ligninolytic enzyme production by $L$. elegans. According to ${ }^{22}$ white rot fungi can be divided into 3 groups based on enzyme production: (i). LiP, MnP and laccase producers, (ii). $\mathrm{MnP}$ and laccase producers, (iii). LiP and laccase producers. The most common group is laccase and $\mathrm{MnP}$ producers and the rarest group are laccase and LiP producers. L. elegans $\mathrm{KSG} 32$ belongs to this group of rare ligninolytic fungi. Some commonly studied white rots and the presence of ligninolytic enzymes are given in Table 2.

Table 2 Commonly studied white rot fungi and their enzyme distribution

\begin{tabular}{|c|c|c|c|c|}
\hline White rot fungi & Laccase & LiP & $M n P$ & Reference \\
\hline Trametes sp. & + & + & + & 11 \\
\hline Phanerochaete chrysosporium & + & + & + & 11 \\
\hline Pleurotus sp. & + & + & + & 11 \\
\hline Ganoderma lucidum & + & + & + & 20 \\
\hline L. elegans KSG 32 & + & + & - & This study \\
\hline Pycnoporus cinnabarinus & + & - & - & 23 \\
\hline Bjerkandera sp. & + & - & + & 24 \\
\hline
\end{tabular}

\section{Dye decolourization studies}

The dye toxicity towards the growth of microorganisms is an important factor in decolorization studies. The growth of $L$. elegans KSG32 on the dye containing PDA plates was not retarded by the presence of the dyes as seen in comparison with the control PDA plate. In the present study the toxicity of dyes was determined by comparing the biomass content of L. elegans KSG32 after 12 -day growth in PDB in the presence and absence (control) of the dye. Studies by ${ }^{26-33}$ using Phanerochaete chrysosporium, showed a reduction in biomass due to dye toxicity. Increased dye concentrations were found to be affecting the fungal growth. ${ }^{17}$ However, reports by ${ }^{34}$ indicate enhanced mycelial growth in the presence of dyes. It is probable that in these cases, the organism may be using the dye as a carbon source. According to, ${ }^{3.5}$ an average concentration of $0.3 \mathrm{~g} / \mathrm{L}$ has been reported in the textile effluent. The results indicate that the dyes used for this study were not having any toxic effects on L. elegans KSG32 growth. Instead, of the dyes, it may be acting as an additional carbon source enhancing the fungal mycelial growth.

Bioremediation of synthetic dyes is efficiently achieved by white rot fungi such as $P$. chrysosporium, due to the low substrate specificity and xenobiotic degradability of its ligninolytic enzymes. ${ }^{7,36,37}$ In the present study L. elegans KSG32 efficiently decolorized naphthol green $\mathrm{B}$ which is a metal complex nitroso dye. This adds to the existing reports on the efficient degradation of metal containing dyes using fungi by Vijaykumar. ${ }^{38}$ These dyes are commonly used due to their high light fastness and good wash properties on substrates like wool, nylon and silk. ${ }^{39}$ The decolorization of naphthol green B under anaerobic conditions by Shewanella oneidensis MR-1 was reported by Xiao. ${ }^{40}$ The commonly used triphenylmethane dye, bromophenol blue decolorization was mainly done by Pleurotus sp. ${ }^{41}$ According to, ${ }^{42}$ complex azo dye structures can be completely mineralized by white rot fungi. P. chrysosporium decolorize orange $\mathrm{G}$ completely and Pleurotus sajorcaju decolorize it only $50 \%$ was reported by Chagas. ${ }^{43}$

\section{FTIR analysis}

Control spectrum showed specific peaks at $3328.80 \mathrm{~cm}^{-1}$ for $-\mathrm{OH}$ stretching vibrations, $2966.38 \mathrm{~cm}^{-1}$ and $2866.93 \mathrm{~cm}^{-1}$ for $-\mathrm{CH}$ stretching vibrations (Figure 7A). The peak at $2354.62 \mathrm{~cm}^{-1}$ corresponds to the stretching vibrations of cyclic bonds. Peaks at $1657.53 \mathrm{~cm}^{-1}$ and $1383.60 \mathrm{~cm}^{-1}$ assigned to carbonyl stretching vibrations as reported by Gahlout. ${ }^{44}$ The peak at $1534.10 \mathrm{~cm}^{-1}$ showed $-\mathrm{N}=\mathrm{O}$ stretching vibrations. ${ }^{45}$ Peaks at $1053.54 \mathrm{~cm}^{-1}$ and $1012.94 \mathrm{~cm}^{-1}$ assigned to SO3Na group vibrations and peak at $687.45 \mathrm{~cm}^{-1}$ for $=\mathrm{C}-\mathrm{H}$ bending of aromatic rings. ${ }^{46}$

The spectrum of decolorized extract showed peak shifts and variation of peak intensities when compared with the control dye spectrum. The highly intense peak at $3445.74 \mathrm{~cm}^{-1}$ for $-\mathrm{OH}$ stretching vibrations in Figure 7B indicates the increase in oxidation process during the decolorization. ${ }^{13}$ The disappearance of the peak at $2866.93 \mathrm{~cm}^{-1}$ and the less intense peak at $2974.19 \mathrm{~cm}^{-1}$ showed the decrease in $-\mathrm{CH}$ stretching. Also, the intensity of cyclic bond vibrations was decreased when compared with control spectrum. The $-\mathrm{N}=\mathrm{O}$ stretching vibrations were completely disappeared and the $\mathrm{SO} 3 \mathrm{Na}$ group vibrations were decreased in the decolorized spectrum. There was a shift in $=\mathrm{C}-\mathrm{H}$ bending from $687.45 \mathrm{~cm}^{-1}$ to $655.31 \mathrm{~cm}^{-1}$ and the peak was widened, this could be due to the decrease in aromaticity. The result shows the involvement of lignin modifying enzymes of white rot fungi in decolorization.

Most studies on dye decolorization focus on laccase due to its ability to degrade both phenolic and non-phenolic compounds. Based on the reports of $^{36}$ and $^{47}$ the efficiency of decolorization by laccase increases in the presence of LiP, which helps to overcome the substrate unspecificity of laccase. In the present study, L. elegans KSG32 produce both laccase and LiP which causes more significant decolorization. The results indicate the potential of this organism for future applications in the decolorization and treatment of pollutants in industrial waste water.

\section{Conclusion}

L. elegans KSG32 with efficient laccase and lignin peroxidase activity was effectively used for the decolorization of synthetic dyes. The selected dyes were found to be non -toxic towards the organism. This property of the organism can be implemented in the bioremediation of colored industrial waste water.

\section{Acknowledgements}

Authors acknowledge Council of Scientific and Industrial Research (CSIR), India for the financial support in the form of fellowship and Cochin University of Science and Technology for providing laboratory facilities. Authors also acknowledge Sophisticated Test and Instrumentation Centre, Kochi for the FTIR analysis.

\section{Conflict of interest}

The author declares no conflict of interest.

\section{References}

1. Khalid A, Arshad M, Crowley D. Bioaugmentation of azo dyes. Germany: Springer Berlin Heidelberg; 2010. p. 1-37. 
2. Carmen Z, Daniela S. Textile organic dyes-characteristics, polluting effects and separation/elimination procedures from industrial effluents-a critical overview. Organic Pollutants Ten Years After the Stockholm Convention-Environmental and Analytical Update, 2012. p. 55-81.

3. Selvam K, Swaminathan K, Chae KS. Decolourization of azo dyes and a dye industry effluent by a white rot fungus Thelephora sp. BioresourTechnol. 2003;88(2):115-119.

4. Kim TH, Park C, Kim S. Water recycling from desalination and purification process of reactive dye manufacturing industry by combined membrane filtration. J Clean Prod. 2005;13(8):779-786.

5. Banat IM, Nigam P, Singh D, et al. Microbial decolorization of textiledyecontaining effluents: a review. Bioresour Technol. 1996;58(3):217227.

6. Gold MH, Alic M. Molecular biology of the lignin-degrading basidiomycete Phanerochaete chrysosporium. Microbiol Rev. 1993;57(3):605-622.

7. Haglund C. Biodegradation of xenobiotic compounds by the white-rot fungus Trametes trogii. Mol Biotech Progr. 1999:30.

8. Piontek K, Smith AT, Blodig W. Lignin peroxidase structure and function. Biochem Soc Trans. 2001;29(Pt 2):111-116.

9. Erden E, Ucar MC, Gezer T, et al. Screening for ligninolytic enzymes from autochthonous fungi and applications for decolorization of Remazole Marine Blue. Braz J Microbiol. 2009;40(2):346-353.

10. Oyadomari M, Shinohara H, Johjima $T$, et al. Electrochemical characterization of lignin peroxidase from the white-rot basidiomycete Phanerochaete chrysosporium. J Mol Catal B: Enzym. 2003;21(4):291297.

11. Eriksson K-EL, Bermek H. Lignin, Lignocellulose, Ligninase. Appl Microbiol. 2009:373-384.

12. Baldrian P. Fungal laccases-occurrence and properties. FEMS microbiol rev. 2006;30(2):215-242.

13. Xu F. Oxidation of phenols, anilines, and benzenethiols by fungal laccases:correlation between activity and redox potentials as well as halide inhibition. Biochemistry. 1996;35(23):7608-7614.

14. McMullan G, Meehan C, Conneely A, et al. Microbial decolourization and degradation of textile dyes. Appl Microbiol Biotechnol. 2001;56(12):81-87.

15. Jarosz-Wilkołazka A, Kochmańska-Rdest J, Malarcz̄yk E, et al. Fungi and their ability to decolourizeazo and anthraquinonic dyes. Enzyme Microb Technol. 2002;30(4):566-572.

16. Toh YC, Yen JJL, Obbard JP, et al. Decolourization of azo dyes by white-rot fungi (WRF) isolated in Singapore. Enzyme Microb Technol. 2003;33(5):569-575.

17. Ali MI, Khalil NM, El-Ghany MNA. Biodegradation of some polycyclic aromatic hydrocarbons by Aspergillus terreus. Afr J Microbiol Res. 2012;6(16):3783-3790.

18. Coll PM, Fernandez-Abalos JM, Villanueva JR, et al. Purification and characterization of a phenoloxidase (laccase) from the lignindegrading basidiomycete PM1 (CECT 2971). Appl Environ Microbiol. 1993;59(8):2607-2613.

19. Tien M, Kirk TK. Lignin-degrading enzyme from the hymenomycete Phanerochaete chrysosporium Burds. Science. 1983;221(4611):661-663.

20. Bourbonnais R, Paice MG, Reid ID, et al. Lignin oxidation by laccase isozymes from Trametes versicolor and role of the mediator 2, 2'-azinobis (3-ethylbenzthiazoline-6-sulfonate) in kraft lignin depolymerization. Appl Environ Microbiol. 1995;61(5):1876-1880.
21. Gupta VK, Tuohy MG, Gaur R. Methods for high- quality DNA extraction from fungi. In: Gupta VK, Tuohy MG, editors. Laboratory protocols in fungal biology, Current methods in Fungal Biology. USA: Springer Science Inc; 2013. p. 403-405.

22. White TJ, Bruns T, Lee SJWT, et al. Amplification and direct sequencing of fungal ribosomal RNA genes for phylogenetics. In PCR protocols: $a$ guide to methods and applications. 1990;18(1):315-322.

23. Altschul SF, Gish W, Miller W, et al. Basic local alignment search tool. $J$ Mol Biol. 1990;215(3):403-410.

24. Lopez MJ, Guisado G, Vargas-Garcia MC, et al. Decolorization of industrial dyes by ligninolytic microorganisms isolated from composting environment. Enzyme Microb Technol. 2006;40(1):42-45.

25. Liu W, Chao Y, Yang X, et al. Biodecolorization of azo, anthraquinonic and triphenylmethane dyes by white-rot fungi and a laccase-secreting engineered strain. Journal of Industrial Microbiology and Biotechnology. 2004;31(3):127-132.

26. Kirk TK, Farrell RL. Enzymatic “combustion":the microbial degradation of lignin. Annu Rev Microbiol. 1987;41(1):465-501.

27. Pointing SB, Pelling AL, Smith GJ, et al. Screening of basidiomycetes and xylariaceous fungi for lignin peroxidase and laccase gene-specific sequences. Mycol Res. 2005;109(01):115-124.

28. Asgher M, Sharif Y, Bhatti HN. Enhanced production of ligninolytic enzymes by Ganoderma lucidum IBL-06 using lignocellulosic agricultural wastes. Int J Chem React Eng. 2010;8(1).

29. Hariharan S, Nambisan P. Optimization of lignin peroxidase, manganese peroxidase, and Lac production from Ganodermalucidum under solid state fermentation of pineapple leaf. Bio Resour. 2012;8(1):250-271.

30. Hatakka A. Biodegradation of lignin. In: Steinbuchel A, Hofrichter M, editors. Biopolymers, Lignin, humic substances, and coal. Germany: Wiley-VCH; 2001. 1:129-180.

31. Eggert C, Temp U, Dean JF, et al. A fungal metabolite mediates degradation of non $\square$ phenolic lignin structures and synthetic lignin by laccase. FEBS Lett. 1996;391(1-2):144-148.

32. de Jong E, Cazemier AE, Field JA, et al. Physiological role of chlorinated aryl alcohols biosynthesized de novo by the white rot fungus Bjerkandera sp. strain BOS55. Appl Environ Microbiol. 1994;60(1):271-277.

33. Kausik S, Kannan P, Sitangshu Bikas S. Modelling the biomass growth and enzyme secretion by the white rot fungus Phanerochaete chrysosporium in presence of a toxic pollutant. J Environ Prot. 2012;3:114-119.

34. Eichlerová I, Homolka L, Nerud F. Decolorization of synthetic dyes by Pleurotus ostreatus isolates differing in ligninolytic properties. Folia microbiol. 2002;47(6):691-695.

35. Rodriguez-Couto S. Treatment of Textile Wastewater by White-rot Fungi: Still a Far Away Reality? Textiles and Light Industrial Science and Technology. 2013;2(3):7.

36. Ollikka P, Alhonmäki K, Leppänen VM, et al. Decolorization of azo, triphenyl methane, heterocyclic, and polymeric dyes by lignin peroxidase isoenzymes from Phanerochaetechrysosporium. Appl Environ Microbiol. 1993;59(12):4010-4016.

37. Robinson T, Chandran B, Nigam P. Studies on the decolourization of an artificial textile-effluent by white-rot fungi in N-rich and $\mathrm{N}$-limited media. Appl Microbiol Biotechnol. 2001;57(5-6):810-814.

38. Vijaykumar MH, Veeranagouda $\mathrm{Y}$, Neelakanteshwar $\mathrm{K}$, et al. Decolorization of 1:2 metal complex dye Acid blue 193 by a newly isolated fungus, Cladosporium cladosporioides. World J Microbiol Biotechnol. 2006;22(2):157-162. 
39. Richard SB, Stephen MB. A greener approach to cotton dyeings. Part 2: Application of 1:2 metal complex acid dyes. Green Chemistry. 2002;4:261-265.

40. Xiao X, Xu CC, Wu YM, et al. Biodecolorization of naphthol green $\mathrm{B}$ dye by Shewanella oneidensis MR-1 under anaerobic conditions. Bioresour Technol. 2012;110:86-90.

41. Radhika R, Jebapriya GR, Gnanadoss JJ. Decolourization of synthetic textile dyes using the edible mushroom fungi I. Pak $J$ BiolSci. $2014 ; 17(2): 248$.

42. Spadaro JT, Gold MH, Renganathan V. Degradation of azo dyes by the lignin-degrading fungus Phanerochaetechrysosporium. Appl Environ Microbiol. 1992;58(8):2397-2401.

43. Chagas EP, Durrant LR. Decolorization of azo dyes by Phanerochaete chrysosporium and Pleurotus sajorcaju. Enzyme Microb Technol. 2001;29(8):473-477.
44. Gahlout M, Gupte S, Gupte A. Optimization of culture condition for enhanced decolorization and degradation of azo dye reactive violet 1 with concomitant production of ligninolytic enzymes by Ganoderma cupreum AG-1. 3 Biotech. 2013;3(2):143-152.

45. Lade HS, Waghmode TR, Kadam AA, et al. Enhanced biodegradation and detoxification of disperse azo dye Rubine GFL and textile industry effluent by defined fungal-bacterial consortium. Int Biodeterior Biodegrad. 2012;72:94-107.

46. Parmar N, Shukla SR. Microbial Decolorization of Reactive Dye Solutions. CLEAN-Soil, Air, Water. 2015;43(10):1426-1432.

47. Hadibarata T, Yusoff ARM, Kristanti RA. Decolorization and metabolism of anthraquionone-type dye by laccase of white-rot fungi Polyporus sp. S133. Water Air Soil Pollut. 2012;223(2):933-941. 